\title{
The exchange rate exposure puzzle: the long and the short of it.
}

\begin{abstract}
The exchange rate exposure puzzle has remained robust to empirical scrutiny despite varied and ever more sophisticated empirical approaches. The difficulty in finding empirical evidence of a link between exchange rate changes and firm returns is more evident at shorter horizons with the prevailing view in the literature being that the puzzle abates when longer horizons are considered. The findings of this paper suggests the long horizon evidence is illusory. Specifically, the application of inference that has good finite sample properties in a long horizon regression setting overturns evidence of long horizon exposure using conventional estimation methods.
\end{abstract}

Keywords:

Exchange rate exposure, Economic exposure, Long horizon regression, Overlapping data.

$J E L$ :

C13, C22, F23, F31.

\section{Introduction}

Financial theory indicates that there should be a relationship between exchange rate movements and firm returns. The failure to find this relationship empirically has been termed the exchange rate exposure puzzle (for a review of the literature see Bartram and Bodnar, 2007). For the most 5 part, the literature has examined the puzzle from a short horizon perspective but there is a branch of the exchange rate exposure literature that suggests the puzzle is less pervasive at longer horizons (for example see: Chow et al., 1997; Dominguez and Tesar, 2006; Aggarwal and Harper, 2010). The rationale here is that it may be possible to hedge against transaction exposure (exposure at shorter horizons) but hedging economic exposure (exposure at longer horizons) is far more difficult. While exposure has become a stylized fact cited by many studies. By deploying the transformed regression (TR) method of Britten-Jones et al. (2011) this paper goes further than the extant literature in addressing the empirical difficulties surrounding the estimation of long horizon exposure regressions, and in doing so provides new evidence that shows that economic exchange rate exposure is illusory and therefore the puzzle is worse than previously thought.

Section 2 presents the TR method, Section 3 discusses the data and results, while Section 4 concludes.

\section{Exchange rate exposure regression and the transformed regression method}

Exchange rate exposure for horizon $k$ is typically tested using the following regression (for example

$$
r_{i, t, t+k}=\beta_{0, i}+\beta_{1} r_{m, t, t+k}+\beta_{2} \Delta s_{t, t+k}+\epsilon_{i, t+1}
$$


where $r_{i, t, t+k}$ is the $k$-period return for firm $i, r_{m, t, t+k}$ is the $k$-period return on the market index and $\Delta s_{t, t+k}$ is the $k$-period change in the relevant exchange rate. Controlling for the movement in the market, exchange rate exposure is found when $\beta_{2}$ is significant.

When testing for long horizon exposure the issue of overlapping data needs to be addressed.

This method aggregates the matrix of explanatory variables transforming the original (overlapping) regression into an equivalent representation of non-overlapping variables. ${ }^{1}$

Adopting the notation of Britten-Jones et al. (2011) we re-express Equation (1) as the following overlapping regression:

$$
A r=X \beta+u
$$

30 matrix with 1's on the main diagonal and the first $k-1$ right off-diagonals and 0's otherwise, and X a matrix of explanatory variables and constant from Equation (1). Britten-Jones et al. (2011) show that $\hat{\beta}$ from Equation (2) can be rewritten in terms of the one period non-overlapping returns, and be estimated using standard OLS on the following TR with transformed explanatory variables $\tilde{X}$ :

$$
\begin{gathered}
r=\tilde{X} \beta+\tilde{u} \\
\tilde{X} \equiv A^{\prime} X\left(X^{\prime} A A^{\prime} X\right)^{-1} X^{\prime} X
\end{gathered}
$$

35 It can be shown that $\hat{\beta}$ using OLS from Equations (2) and (3) are identical and is shown in Equation (5):

$$
\hat{\beta}=\left(X^{\prime} X\right)^{-1} X^{\prime} A r
$$

Crucially while $\hat{\beta}$ from the overlapping and transformed regressions are the same, using the transformed regression should result in improved inference as $\hat{\beta}-\beta$ from the latter depends on the autocorrelation structure of noise from the transformed regression $(\tilde{u})$ as opposed to the noise in the overlapping regression $(u)$. Britten-Jones et al. (2011) shows that inference can be garnered by simply (i) constructing the transformed regressor matrix $\tilde{X}$ (ii) using regression (3) (iii) relying on conventional standard errors. Further, their finite sample analysis indicates substantial improvements in inference when using the TR with inference from conventional OLS, White (1980), and Newey and West (1987) standard errors as compared with the same inference on the untransformed data.

\section{Data and Results}

We estimate the exchange rate exposure regression using data from 1996:01-2015:12 from Datastream for 2011 firms sampled across 10 economies with varying degrees of development (Australia, Canada,

\footnotetext{
${ }^{1}$ In this setting the main issue is the proper calculation of standard errors when using overlapping data as the use of such data results in strong serial correlation in regression residuals. As discussed in the literature, commonly used methods to deal with this are inadequate given the strength of the serial correlation.
} 
China, India, Indonesia, Japan, South Africa, Thailand, United States, and United Kingdom). ${ }^{2}$

50 Appendix A shows the number of firms per economy. We use monthly data, trade weighted exchange rates and a valued weighted market index for each economy. ${ }^{3}$ We consider horizons ranging from 1 month to 5 years.

Table 1 summarizes the exchange rate exposure results from Equation (1) using OLS as well as Newey and West (1987) heteroskedasticity autocorrelation consistent (HAC) standard errors. Unreported results using White (1980) standard errors yield similar results. The first observation to make is that both methods indicate some evidence of predictability at the 1-month horizon that increases as a function of $k$. A country average of the proportion of significant OLS results indicates approximately $28 \%$ of firms exhibit exchange rate exposure when $k=1$ month, and this grows to over $80 \%$ when $k=5$ years. As expected these proportions are higher than those documented in the early literature as more recent data is used (see Inci and Lee, 2014). Overall, the results of Table 1 are in keeping with earlier studies indicating it is harder to hedge exchange rate exposure at longer horizons.

The results in Table 2 repeat the analysis but address the issue of data overlapping by applying the TR method. Strikingly, the results of Table 2 overturn Table 1 and the extant view in the iterature. The table shows that as $k$ increases the proportion of firms that exhibit exposure using either TR method is far below that indicated in Table 1 and thus there is less evidence of exposure. This is true for all countries tested, with a country average of the proportion of significant results dropping below $10 \%$ at the 5-year horizon. These striking results suggest a revision of the prevailing view that exposure becomes more evident at longer horizons. ${ }^{4}$

\section{Conclusion}

This paper examines the prevailing view in the literature that firms are subject to economic (long horizon) exchange rate exposure. It applies the approach of Britten-Jones et al. (2011) to address the problem of overlapping data to 2011 firms across 10 diverse economies and over a variety of horizons. Results clearly indicate that the evidence in favor of economic exposure is overturned when properly accounting for the effect of overlapping observations. This suggests the exchange rate exposure puzzle is more perplexing than ever.

\footnotetext{
${ }^{2}$ We do this as Bartram and Bodnar (2012) show emerging economies are more likely to exhibit exposure than developed countries.

${ }^{3}$ The literature discusses the use of an equally weighted market index as an alternative. Results using these data do not qualitatively change our findings. This is also true when using data sampled at weekly instead of monthly intervals.

${ }^{4}$ We note that Australia, Canada, and to a lesser extent South Africa have notably higher exposure at longer horizons than other economies. This we attribute to a commodity currency effect (as Chen et al., 2010 note these three currencies are viewed as major commodity currencies). Unreported results showing firm exposure by industry type supports this finding for Australia and Canada.
} 
Appendix A Data

Table A1

Data composition: number of firms by country

\begin{tabular}{lc}
\hline Country & Number of firms \\
\hline Australia & 78 \\
Canada & 110 \\
China & 167 \\
India & 241 \\
Indonesia & 172 \\
Japan & 255 \\
South Africa & 67 \\
Thailand & 243 \\
United Kingdom & 321 \\
United States & 357 \\
\hline Total & 2011 \\
\hline
\end{tabular}




\section{References}

Aggarwal, R., Harper, J. T., 2010. Foreign exchange exposure of domestic corporations. Journal of International Money and Finance 29 (8), 1619-1636.

Bartram, S. M., Bodnar, G. M., 2007. The exchange rate exposure puzzle. Managerial Finance $33(9), 642-666$.

Bartram, S. M., Bodnar, G. M., 2012. Crossing the lines: The conditional relation between exchange rate exposure and stock returns in emerging and developed markets. Journal of International Money and Finance 31 (4), 766-792.

Britten-Jones, M., Neuberger, A., Nolte, I., 2011. Improved inference in regression with overlapping observations. Journal of Business Finance \& Accounting 38 (5-6), 657-683.

Chen, Y.-C., Rogoff, K. S., Rossi, B., 2010. Can exchange rates forecast commodity prices? The Quarterly Journal of Economics 125 (3), 1145-1194.

90 Chow, E. H., Lee, W. Y., Solt, M. E., 1997. The economic exposure of US multinational firms. Journal of Financial Research 20 (2), 191-210.

Dominguez, K. M., Tesar, L. L., 2006. Exchange rate exposure. Journal of international Economics $68(1), 188-218$.

Inci, A., Lee, B. S., 2014. Dynamic relations between stock returns and exchange rate changes. ${ }_{95} \quad$ European Financial Management 20 (1), 71-106.

Newey, W. K., West, K. D., 1987. A simple, positive semi-definite, heteroskedasticity and autocorrelation consistent covariance matrix. Econometrica 55 (3), 703-08.

White, H., 1980. A heteroskedasticity-consistent covariance matrix estimator and a direct test for heteroskedasticity. Econometrica: Journal of the Econometric Society, 817-838. 
Table 1

Exchange rate exposure: overlapping data

\begin{tabular}{|c|c|c|c|c|c|c|}
\hline & \multicolumn{3}{|c|}{ Transaction exposure } & \multicolumn{3}{|c|}{ Economic exposure } \\
\hline & 1 month & 3 months & 12 months & 2 years & 3 years & 5 years \\
\hline \multicolumn{7}{|c|}{ Australia } \\
\hline OLS & 29.48 & 51.29 & 61.53 & 69.23 & 76.93 & 85.9 \\
\hline $\mathrm{HAC}$ & 25.64 & 38.46 & 38.46 & 50.00 & 56.41 & 69.23 \\
\hline \multicolumn{7}{|c|}{ Canada } \\
\hline OLS & 18.18 & 40.9 & 68.19 & 81.81 & 80.00 & 81.82 \\
\hline $\mathrm{HAC}$ & 12.73 & 29.09 & 51.82 & 54.55 & 63.63 & 59.09 \\
\hline \multicolumn{7}{|c|}{ China } \\
\hline OLS & 2.40 & 9.58 & 51.49 & 75.45 & 90.42 & 94.01 \\
\hline HAC & 3.00 & 7.19 & 22.76 & 53.89 & 83.84 & 86.83 \\
\hline \multicolumn{7}{|l|}{ India } \\
\hline OLS & 7.05 & 21.58 & 38.17 & 54.36 & 65.98 & 78.43 \\
\hline $\mathrm{HAC}$ & 9.13 & 13.69 & 14.94 & 27.38 & 48.14 & 65.14 \\
\hline \multicolumn{7}{|c|}{ Indonesia } \\
\hline OLS & 62.79 & 69.19 & 73.26 & 74.42 & 68.61 & 72.09 \\
\hline $\mathrm{HAC}$ & 52.91 & 58.14 & 65.70 & 61.05 & 53.49 & 52.90 \\
\hline \multicolumn{7}{|c|}{ Japan } \\
\hline OLS & 23.14 & 44.31 & 78.82 & 81.18 & 84.32 & 83.92 \\
\hline $\mathrm{HAC}$ & 18.04 & 27.84 & 51.38 & 60.00 & 65.10 & 65.89 \\
\hline \multicolumn{7}{|c|}{ South Africa } \\
\hline OLS & 53.73 & 59.70 & 70.15 & 73.14 & 77.61 & 83.58 \\
\hline $\mathrm{HAC}$ & 53.73 & 50.75 & 49.26 & 53.74 & 65.67 & 62.69 \\
\hline \multicolumn{7}{|c|}{ Thailand } \\
\hline OLS & 38.27 & 51.85 & 59.26 & 55.96 & 66.66 & 77.37 \\
\hline HAC & 28.39 & 27.99 & 36.63 & 31.28 & 45.67 & 58.02 \\
\hline \multicolumn{7}{|c|}{ United Kingdom } \\
\hline OLS & 22.74 & 41.74 & 63.24 & 73.83 & 79.13 & 83.49 \\
\hline $\mathrm{HAC}$ & 19.63 & 23.36 & 31.78 & 49.53 & 58.26 & 67.92 \\
\hline \multicolumn{7}{|c|}{ United States } \\
\hline OLS & 24.93 & 41.46 & 64.43 & 70.87 & 77.59 & 84.88 \\
\hline $\mathrm{HAC}$ & 23.81 & 28.85 & 45.38 & 52.10 & 62.19 & 73.39 \\
\hline
\end{tabular}

This table presents the exchange rate exposure results using Equation (1) with OLS and Newey and West's (1987) (HAC) standard errors. The results show the percentage of firms with significant exposure at the $5 \%$ level. 
Table 2

Exchange rate exposure: transformed data

\begin{tabular}{|c|c|c|c|c|c|c|}
\hline & \multicolumn{3}{|c|}{ Transaction exposure } & \multicolumn{3}{|c|}{ Economic exposure } \\
\hline & 1 month & 3 months & 12 months & 2 years & 3 years & 5 years \\
\hline \multicolumn{7}{|c|}{ Australia } \\
\hline OLS & 29.48 & 24.35 & 19.23 & 16.67 & 19.23 & 17.95 \\
\hline HAC & 25.64 & 23.07 & 21.79 & 17.95 & 21.79 & 19.23 \\
\hline \multicolumn{7}{|c|}{ Canada } \\
\hline OLS & 18.18 & 14.55 & 18.18 & 14.55 & 15.46 & 11.82 \\
\hline $\mathrm{HAC}$ & 12.73 & 19.09 & 22.73 & 25.46 & 28.18 & 24.54 \\
\hline \multicolumn{7}{|c|}{ China } \\
\hline OLS & 2.40 & 0.00 & 0.00 & 0.60 & 1.20 & 1.20 \\
\hline HAC & 3.00 & 3.00 & 4.79 & 4.79 & 4.19 & 7.19 \\
\hline \multicolumn{7}{|l|}{ India } \\
\hline OLS & 7.05 & 4.56 & 0.82 & 0.83 & 1.24 & 2.48 \\
\hline $\mathrm{HAC}$ & 9.13 & 9.54 & 3.73 & 2.07 & 4.98 & 3.73 \\
\hline \multicolumn{7}{|c|}{ Indonesia } \\
\hline OLS & 62.79 & 56.39 & 19.19 & 10.46 & 2.90 & 4.65 \\
\hline $\mathrm{HAC}$ & 52.91 & 48.26 & 12.79 & 6.40 & 1.16 & 1.16 \\
\hline \multicolumn{7}{|c|}{ Japan } \\
\hline OLS & 23.14 & 20.78 & 13.73 & 6.28 & 7.06 & 0.00 \\
\hline $\mathrm{HAC}$ & 18.04 & 21.96 & 13.33 & 7.06 & 7.85 & 0.00 \\
\hline \multicolumn{7}{|c|}{ South Africa } \\
\hline OLS & 53.73 & 40.30 & 14.93 & 4.48 & 7.46 & 17.91 \\
\hline $\mathrm{HAC}$ & 53.73 & 41.80 & 23.88 & 14.93 & 11.94 & 23.88 \\
\hline \multicolumn{7}{|c|}{ Thailand } \\
\hline OLS & 38.27 & 29.63 & 14.82 & 4.12 & 2.47 & 1.64 \\
\hline $\mathrm{HAC}$ & 28.39 & 16.05 & 11.94 & 2.88 & 1.23 & 2.47 \\
\hline \multicolumn{7}{|c|}{ United Kingdom } \\
\hline OLS & 22.74 & 18.06 & 6.23 & 7.79 & 7.16 & 5.29 \\
\hline $\mathrm{HAC}$ & 19.63 & 14.95 & 5.29 & 2.49 & 1.24 & 1.56 \\
\hline \multicolumn{7}{|c|}{ United States } \\
\hline OLS & 24.93 & 16.81 & 9.24 & 3.92 & 3.64 & 2.80 \\
\hline $\mathrm{HAC}$ & 23.81 & 22.97 & 16.80 & 11.48 & 7.00 & 4.48 \\
\hline
\end{tabular}

This table presents the exchange rate exposure results using Equation (3) with OLS and Newey and West's (1987) (HAC) standard errors. The results show the percentage of firms with significant exposure at the $5 \%$ level. 